\title{
Initiation Factor
}

National Cancer Institute

\section{Source}

National Cancer Institute. Initiation Factor. NCI Thesaurus. Code C17461.

One of several soluble proteins involved in the initiation of protein or RNA synthesis. 